\title{
Comparative analyses of proteins from Haemophilus influenzae biofilm and planktonic populations using metabolic labeling and mass spectrometry
}

\author{
Deborah MB Post ${ }^{1}$, Jason M Held², Margaret R Ketterer ${ }^{3}$, Nancy J Phillipss ${ }^{4}$, Alexandria Sahu' \\ Michael A Apicella ${ }^{3}$ and Bradford W Gibson ${ }^{1,4^{*}}$
}

\begin{abstract}
Background: Non-typeable $\mathrm{H}$. influenzae (NTHi) is a nasopharyngeal commensal that can become an opportunistic pathogen causing infections such as otitis media, pneumonia, and bronchitis. NTHi is known to form biofilms. Resistance of bacterial biofilms to clearance by host defense mechanisms and antibiotic treatments is well-established. In the current study, we used stable isotope labeling by amino acids in cell culture (SILAC) to compare the proteomic profiles of NTHi biofilm and planktonic organisms. Duplicate continuous-flow growth chambers containing defined media with either "light" $(\mathrm{L})$ isoleucine or "heavy" $(\mathrm{H}){ }^{13} \mathrm{C}_{6}$-labeled isoleucine were used to grow planktonic $(\mathrm{L})$ and biofilm $(H)$ samples, respectively. Bacteria were removed from the chambers, mixed based on weight, and protein extracts were generated. Liquid chromatography-mass spectrometry (LC-MS) was performed on the tryptic peptides and 814 unique proteins were identified with 99\% confidence.
\end{abstract}

Results: Comparisons of the NTHi biofilm to planktonic samples demonstrated that 127 proteins showed differential expression with $p$-values $\leq 0.05$. Pathway analysis demonstrated that proteins involved in energy metabolism, protein synthesis, and purine, pyrimidine, nucleoside, and nucleotide processes showed a general trend of downregulation in the biofilm compared to planktonic organisms. Conversely, proteins involved in transcription, DNA metabolism, and fatty acid and phospholipid metabolism showed a general trend of upregulation under biofilm conditions. Selected reaction monitoring (SRM)-MS was used to validate a subset of these proteins; among these were aerobic respiration control protein ArcA, NAD nucleotidase and heme-binding protein A.

Conclusions: The present proteomic study indicates that the NTHi biofilm exists in a semi-dormant state with decreased energy metabolism and protein synthesis yet is still capable of managing oxidative stress and in acquiring necessary cofactors important for biofilm survival.

Keywords: Non-typeable Haemophilus influenzae, Metabolic labeling, Biofilms, Mass spectrometry

\section{Background}

Non-typeable Haemophilus influenzae (NTHi) is a Gram-negative organism that is a typical component of the normal human nasopharyngeal flora. Under certain conditions, this bacterium can also be an opportunistic pathogen causing upper and lower respiratory tract infections such

\footnotetext{
*Correspondence: bgibson@buckinstitute.org

${ }^{1}$ The Buck Institute for Research on Aging, Novato, CA 94945, USA

${ }^{4}$ The University of California San Francisco, San Francisco, CA 94143, USA
} Full list of author information is available at the end of the article as otitis media, pneumonia, and bronchitis [1-4]. Infants, young children, the elderly, and persons suffering from chronic obstructive pulmonary disease (COPD) are the most common populations impacted by these opportunistic infections $[1,4,5]$.

$H$. influenzae is able to form biofilms under both in vitro and in vivo conditions [6-12]. These biofilms are bacterial communities that exhibit characteristics which differentiate them from planktonic organisms [13]. One of these unique biofilm characteristics is resistance to

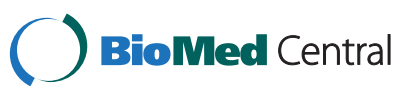

(c) 2014 Post et al.; licensee BioMed Central. This is an Open Access article distributed under the terms of the Creative Commons Attribution License (http://creativecommons.org/licenses/by/4.0), which permits unrestricted use, distribution, and reproduction in any medium, provided the original work is properly credited. The Creative Commons Public Domain Dedication waiver (http://creativecommons.org/publicdomain/zero/1.0/) applies to the data made available in this article, unless otherwise stated. 
clearance by antibiotics and the immune system [13-16]. This resistance is most likely responsible for the recurrent infections sometimes seen with $H$. influenzae [17-19]. The generation of a biofilm matrix is also a typical characteristic of a biofilm [20]. The $H$. influenzae biofilm matrix has been shown to consist of a number of components including double-stranded DNA, type IV pilin protein and sialylated lipooligosaccharide (LOS) [6,10,21-25]. The biofilm matrix typically generates an oxygen depleted environment within the biofilm and at its base. Nutrients are transported from the outer periphery of the matrix to its lower layers through nutrient channels. This matrix most likely plays a role in resistance to host defenses and antimicrobial therapies.

Several studies have been conducted to examine the components of the $H$. influenzae biofilm matrix, but to date no study has been initiated to examine the differences between the proteomic profiles of $H$. influenzae biofilm and planktonic bacteria. In the present study we utilize stable isotope labeling of amino acids in cell culture (SILAC) combined with mass spectrometry [26-28] to compare proteins expressed in biofilm and planktonic bacteria. Our group and others have successfully utilized SILAC to compare bacterial populations grown under differing conditions [29-33]. SILAC incorporates an amino acid labeled with a heavy stable isotope into one population; following proteolytic digestion, any peptides containing the labeled amino acid are then shifted by a specific mass. This mass shift allows one to directly compare the protein levels of the two test populations upon mixing and subsequent LC/MS analysis. In the present study, ${ }^{13} \mathrm{C}_{6}$-isoleucine was incorporated into biofilm-grown $H$. influenzae. These bacteria were compared to planktonic $H$. influenzae grown in normal isoleucine. These populations were subsequently compared using both MS/MS analyses as well as selected reaction monitoring (SRM)-MS analyses. Mass spectrometry-based proetomic analyses enabled us to generate a list of proteins of interest. Targeted quantitative analyses of a subset of these proteins were subsequently performed using SRM-MS.

\section{Methods}

\section{Bacterial strains and growth conditions}

The previously isolated non-typeable $H$. influenzae strain 2019 was utilized for all studies [34]. Bacteria were grown on agar culture plates made with defined RPMI medium, containing either normal isoleucine (planktonic cultures) or with heavy ${ }^{13} \mathrm{C}_{6}$-labeled isoleucine (biofilm cultures) (Cambridge Isotope Labs, Andover, MA). Inoculation samples were grown in liquid defined RPMI medium, containing the same isoleucine as the plate cultures. Biofilm and planktonic organisms were grown in specially designed biofilm growth chambers, which were set-up as previously described except glass beads were used instead of granite pieces [35]. Two large growth chambers were set-up using the appropriate form of isoleucine, and after three days of growth, the planktonic bacteria ("light") were collected from the liquid media from one chamber, and the biofilm growth ("heavy") was collected from the glass beads of the other chamber (Figure 1).

Confirmation that the bacteria grew as a biofilm on the glass beads was obtained using scanning electron microscopy (Figure 1). Samples were prepared by lifting the beads carefully out of the chamber and gently immersing them in a solution of $1 \% \mathrm{OsO}_{4}$ in perfluorocarbon (Fluorinert FC72 from 3 M Specialty Fluids, St. Paul, MN). The samples were held stationary in this solution at room temperature for $3 \mathrm{~h}$, and then washed in 3 changes of perfluorocarbon, followed by dehydration in 100\% ethanol and

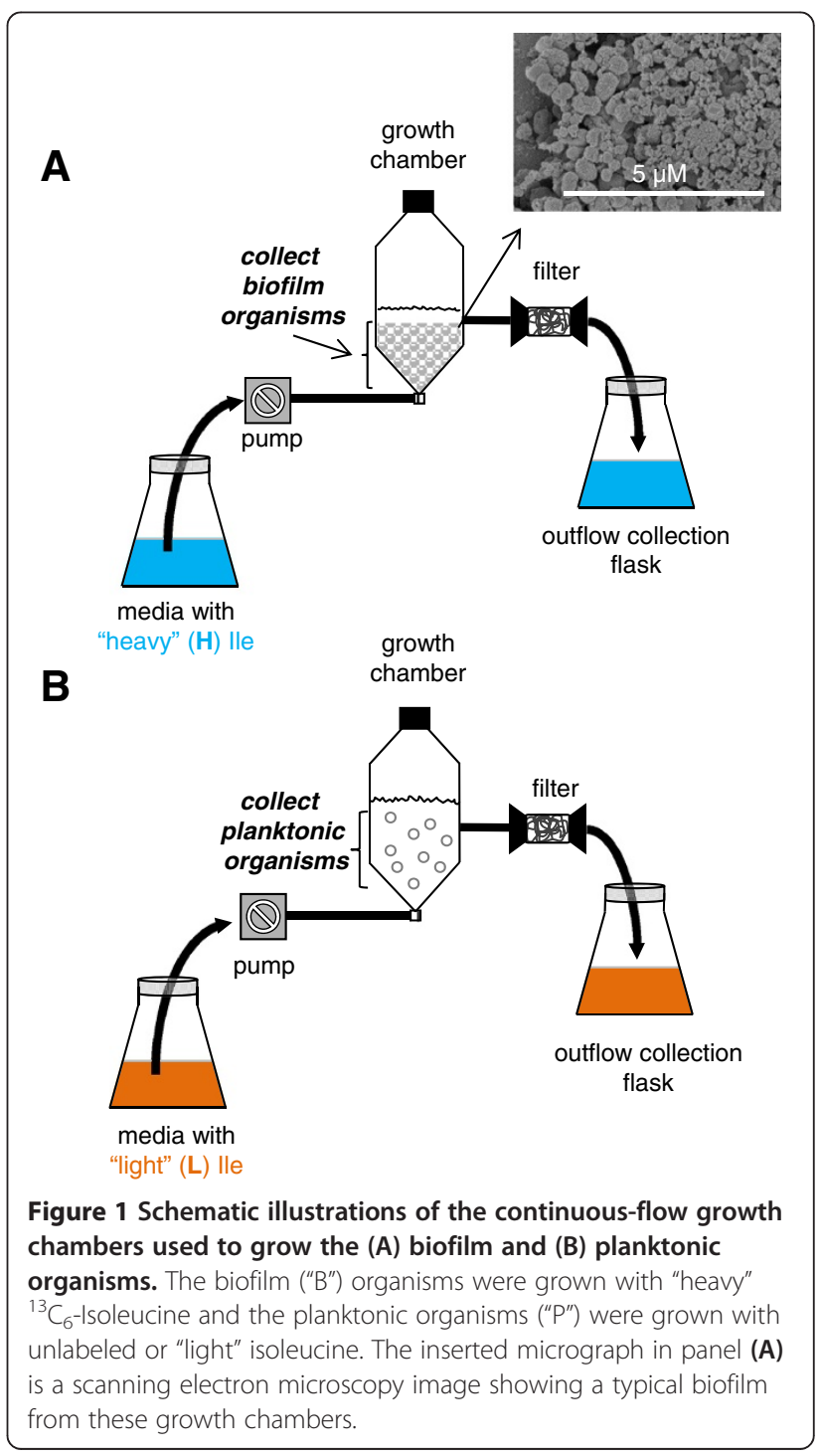


final clearance in hexamethyl-disilazane (Polysciences, Inc., Warrington, PA). The beads were mounted on $\mathrm{Al}$ stubs, sputter-coated with $\mathrm{Au}-\mathrm{Pd}$, and viewed with the Hitachi S4800 scanning electron microscope, housed at the University of Iowa Central Microscopy Research Facility, at an accelerating voltage of $2.0 \mathrm{kV}$.

\section{Protein sample preparation}

Biofilm and planktonic organisms were lyophilized to dryness, weighed, and combined at a ratio to yield equivalent levels of total protein (2:1, biofilm:planktonic). As can be seen in Figure 2, sequential protein extracts were generated using the Bio-Rad Ready Prep Sequential extraction kit (Bio-Rad, Hercules, CA) which generates three sequential protein fractions: soluble, urea-soluble, and SDSsoluble. Bacteria were suspended in $40 \mathrm{mM}$ Tris, sonicated five times for $30 \mathrm{sec}$ each with $1 \mathrm{~min}$ rest intervals on ice, and centrifuged at $16,000 \times g$ for $3 \mathrm{~min}$. The supernatant of this was designated "extract one", the soluble extract. The pellet was suspended in $8 \mathrm{M}$ urea, $4 \%$ CHAPS, and $12 \mathrm{mM}$ tributyl phosphine and was subsequently centrifuged. The supernatant from this was designated "extract two" (urea soluble fraction). The insoluble pellet was washed twice, suspended in 2\% SDS, boiled for $10 \mathrm{~min}$, and designated "extract three" (SDS soluble fraction). The amount of protein in each extract was determined and $60 \mu \mathrm{g}$ of protein from each extract was loaded into separate lanes of a 4-12\% SDS-PAGE gel (NuPage, Life Technologies, Carlsbad, CA). Samples were run $2 \mathrm{~cm}$ into the gel and visualized with Simply Blue Safe Stain (Life Technologies), and manual ingel trypsin digestion was performed. Proteins were excised (5-6 bands excised per extract) from the gels and destained and dehydrated with acetonitrile (50\% acetonitrile/ $25 \mathrm{mM}$ $\mathrm{NH}_{4} \mathrm{HCO}_{3}$ ). Proteins were reduced with $10 \mathrm{mM}$ DTT in $25 \mathrm{mM} \mathrm{NH}_{4} \mathrm{HCO}_{3}$ for $1 \mathrm{~h}$ at $56^{\circ} \mathrm{C}$ and subsequently alkylated with $55 \mathrm{mM}$ iodoacetamide for $45 \mathrm{~min}$ at room temperature. Proteins were digested with trypsin using a trypsin concentration of 1:20 (trypsin:protein) for 16-18 h at $37^{\circ} \mathrm{C}$. Peptides were first extracted with water and subsequently with $50 \%$ acetonitrile $/ 5 \%$ formic acid. Samples were concentrated under vacuum to a final volume of 5-10 $\mu$ l. Approximately $5-10 \mu \mathrm{l}$ of $5 \%$ acetonitrile $/ 0.5 \%$ formic acid was added to the samples to achieve a final volume of $15 \mu \mathrm{l}$.

\section{MALDI-TOF analyses}

To assess proper incorporation of the heavy-labeled isoleucine, peptide samples were initially evaluated by matrix-assisted laser desorption ionization time-of-flight (MALDI-TOF) mass spectrometry on a Voyager DE-STR mass spectrometer (AB Sciex, Concord, Canada) operating in the positive-ion reflectron mode under delayed extraction conditions: $200 \mathrm{~ns}$ delay time, with a grid voltage of $66.5 \%$ of full acceleration voltage $(25 \mathrm{kV})$. Samples were mixed 1:1 with $\alpha$-cyano-4-hydroxycinnamic acid (CHCA) matrix and spotted onto a stainless steel target. Mass spectra were acquired, averaged (typically 100 laser shots), and externally calibrated with a standard peptide mixture consisting of angiotensin I, and ACTH fragments 1-17, 18-39, and 7-38 (Bachem, Torrance, CA).

\section{Nano-LC-ESI MS/MS analyses}

To compare the relative expression levels of proteins between the biofilm and planktonic populations, peptides
A

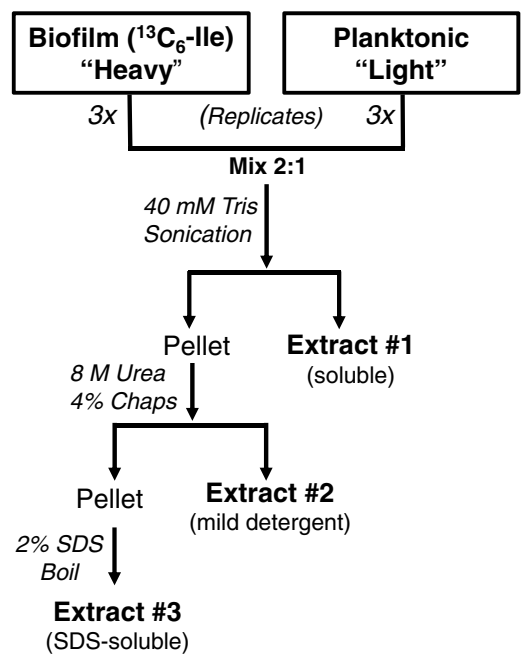

B

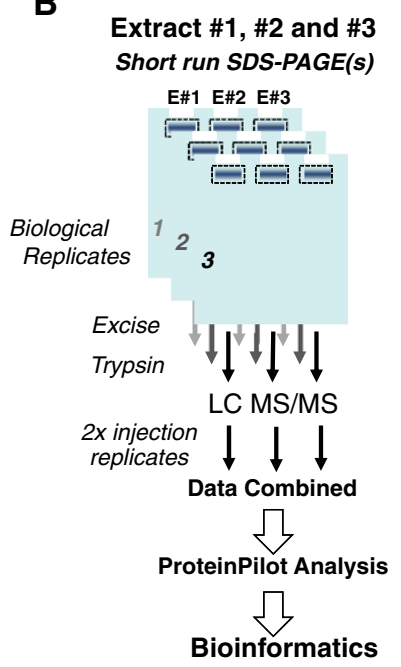

Figure 2 Workflow of sample preparation and analyses. (A) Three sequential extracts were generated in 3 biological replicates and (B) were further separated by SDS-PAGE to enhance protein identification and quantification coverage. The data obtained from the LC/MS experiments (2 injections replicates per sample) were combined for each biological replicate and searched using Protein Pilot. 
generated after proteolytic digestion of all three extracts were analyzed by reverse-phase nano-HPLC-MS/MS using an Eksigent nano-LC 2D HPLC system that was directly connected to a quadropole-TOF mass spectrometer (QSTAR Elite, AB Sciex, Concord, Canada). Peptides were loaded onto a guard column (C18 Acclaim PepMap100, $300 \mu \mathrm{m}$ I.D. $\times 5 \mathrm{~mm}, 5 \mu \mathrm{m}$ particle size, $100 \AA$ pore size, Dionex, Sunnyvale, CA) and washed with loading solvent for $10 \mathrm{~min}(98 \%$ solvent A, 2\% solvent $\mathrm{B}$, where solvent $\mathrm{A}$ is $0.1 \%$ formic acid in $98 \% \mathrm{H}_{2} \mathrm{O}$, $2 \%$ acetonitrile and solvent $\mathrm{B}$ is $0.1 \%$ formic acid in $98 \%$ acetonitrile, $2 \% \mathrm{H}_{2} \mathrm{O}$ ) at a flow rate of $20 \mu \mathrm{l} / \mathrm{min}$. Samples were then transferred onto a C18 nano-HPLC analytical column (C18 Acclaim PepMap100, $75 \mu \mathrm{m}$ I.D. $\times$ $15 \mathrm{~cm}, 3 \mu \mathrm{m}$ particle size, $100 \AA$ pore size, Dionex) and eluted at a flow rate of $300 \mathrm{~nL} / \mathrm{min}$ using either an $\sim 2 \mathrm{~h}$ (extracts 2 and 3 ) or an $\sim 3 \mathrm{~h}$ gradient (extract 1 ). The gradient for the $2 \mathrm{~h}$ runs was: $2-40 \%$ solvent B in A (from 0-60 min), 40-90\% solvent B in A (from 60$75 \mathrm{~min}$ ) and $90 \%$ solvent B in A (from 74-85 min), for a total of $120 \mathrm{~min}$ including column equilibration. The gradient for the $3 \mathrm{~h}$ runs was: $98 \%$ solvent A in B (from 0-5 min), 2-40\% solvent B in A (from 5-125 min), 40$90 \%$ solvent B in A (from 125-140 min), and 90\% solvent B in A (from 140-149 min) for a total of $180 \mathrm{~min}$ including column equilibration. Electrospray ionization mass spectra (ESI-MS) and tandem mass spectra (ESI-MS/ MS) were recorded in positive-ion mode with a resolution of 12,000-15,000 FWHM. An ion spray voltage of $2300 \mathrm{~V}$, curtain gas of $20 \mathrm{psi}$, ion source gas of $17 \mathrm{psi}$, and an interface heater temperature of $100^{\circ} \mathrm{C}$ were used for acquisition of the data. For collision induced dissociation tandem mass spectrometry (CID-MS/MS), the mass window for precursor ion selection of the quadrupole mass analyzer was set to $\pm 1 \mathrm{~m} / z$. Information dependent acquisition was utilized for MS/MS data acquisition. Two injection replicates were run for all samples.

\section{Data analyses of ESI-MS and MS/MS data}

All files generated from the QSTAR Elite were analyzed using Protein Pilot 4.1 (revision 460) running the Paragon Algorithm 4.0.0.0, 459 (Applied Biosystems) [36] with a custom database consisting of the predicted protein sequences from $H$. influenzae strain 86-028NP [37]. Search parameters included: sample type was defined as SILAC (Ile + 6), Cys alkylation method was iodoacetamide, instrument type was QSTAR ESI, and trypsin was the proteolytic enzyme. A "thorough search" was then performed with both 'quantitate' and 'bias correction' features selected. Imperfect 1:1 mixing of the samples was corrected for in the dataset by this bias correction factor, so reported $\mathrm{H}: \mathrm{L}$ ratios were normalized allowing direct comparisons to be made between datasets. False Discovery Rate Analysis (FDR) was performed using the default setting for the "detected protein threshold [Ununsed ProtScore (Conf)]" at $>0.05$ (10.0\%). The Proteomics System Performance Evaluation Pipeline (PSPEP) tool was used to generate the FDR analyses using a concatenated forward and reverse decoy database to search the data. The output from this analysis shows the FDR at the spectral, peptide and protein levels [38]. In the present study, we included in our datasets only proteins with an "Unused ProtScore" of $\geq 2.0$, which corresponds to a protein confidence cut-off threshold of $99 \%$. At this protein confidence threshold, the protein global false discovery rate (FDR) from fit of the data was $0.0048 \%$ or lower in all of the proteomics datasets. The default setting of "Confidence Percent Threshold for Including Self In Quant" within the "ProteinPilot.exe.config" file was changed from 15\% to $50 \%$, thus only peptides with a confidence score of at least $50 \%$ were used to derive the $\mathrm{H}: \mathrm{L}$ ratios for protein quantitation.

All of the output ratios for the quantitative SILAC results were expressed as $\mathrm{H}: \mathrm{L}$ or biofilm:planktonic (B:P). Only quantified proteins with at least two peptides identified and overall $\mathrm{p}$-values $\leq 0.05$ were included in our final datasets of the differentially expressed proteins, a fold-change threshold was not applied to the data. Predicted protein roles were determined using the role identification tool from the J. Craig Venter Institute Comprehensive Microbial Resource website (http://cmr. jcvi.org/cgi-bin/CMR/CmrHomePage.cgi) [39]. In a few cases this search generated a predicted protein role as "unknown". These proteins were further investigated using the "protein knowledgebase (UniProtKB)" from the UniProt website (http://www.uniprot.org/) [40], and if further information was obtained, the role was changed appropriately. Protein localization was predicted using the web-based version of the PSORTb tool version 3.0.2 (http://www.psort.org/psortb/index.html) [41].

\section{LC-SRM/MS}

To increase selectivity and sensitivity of our differential measurements, a select group of peptides were targeted for analysis by nano-LC-SRM/MS on a 4000 QTRAP hybrid triple quadrupole/linear ion-trap mass spectrometer (AB Sciex). Chromatography was performed using a NanoLC-2D LC system (Eksigent, Dublin, CA) with solution A ( $0.1 \%$ formic acid) and solution B (90\% acetonitrile in $0.1 \%$ formic acid). Samples were loaded onto a trap column at $5 \mu \mathrm{l} / \mathrm{min}$ onto a $5 \mathrm{~mm} \times 300 \mu \mathrm{m}$ reversed phase Dionex C18 trap column ( $5 \mu \mathrm{m}, 100 \AA$ ) for $10 \mathrm{~min}$ and eluted at $300 \mathrm{~nL} / \mathrm{min}$ with a gradient of $2-70 \%$ solution B over 32 min using an in-house packed Integrafrit analytical column $(75 \mu \mathrm{m}$ I. D., New Objective, Woburn, MA) with 10-12 cm of ReproSil-Pur C18-AQ $3 \mu \mathrm{m}$ reversed phase resin (Dr. Maisch GmbH, Germany). Peptides were ionized using a PicoTip emitter $(75 \mu \mathrm{m}, 15 \mu \mathrm{m}$ 
tip, New Objective). Data acquisition was performed using Analyst 1.5 (AB Sciex) with an ion spray voltage of $2450 \mathrm{~V}$, curtain gas of $10 \mathrm{psi}$, nebulizer gas of $20 \mathrm{psi}$, and an interface heater temperature of $150^{\circ} \mathrm{C}$. To develop SRM transitions, data files from the QSTAR Elite runs were imported into the publicly available software Skyline. A detailed description of the software is described elsewhere $[42,43]$. SRM transitions were selected from proteins predicted to have differential expression between the biofilm and planktonic samples. In total, 368 transitions were analyzed in a single LC-SRM/MS analysis with identical dwell times, collision energies, declustering potentials and collision cell exit potentials for each pair of labeled and unlabeled peptides. All of the soluble extract fractions from all of the biological replicates were analyzed by SRM, except one fraction from experiment \#2 because the sample was lost due to technical difficulties. Skyline software was utilized for data analyses. The data from the strongest fraction and the best transition was extracted from Skyline and analyzed. Observed peptides needed to have relatively consistent retention times across the various biological replicates and between the "heavy" and "light" versions of the peptide and they also needed to have a signal to noise ratio of at least 2:1 to be included in our dataset. The observed bias factor for each biological replicate was applied to the data extracted from the best transition. Average ratios were calculated by converting ratios to $\log 2$, averaging and then converting these results back to normal numbers.

\section{Data accession}

All raw data associated with this manuscript may be downloaded from the massIVE ftp site at $\mathrm{ftp}$ :// MSV000078838@massive.ucsd.edu [44].

\section{Results}

\section{Sample preparation}

RPMI media supplemented with either normal isoleucine ("light") or ${ }^{13} \mathrm{C}_{6}$-isoleucine ("heavy") was used to culture the planktonic and biofilm organisms, respectively. Both samples were prepared utilizing large growth chambers as shown in Figure 1. The presence of a typical biofilm on the glass beads was confirmed using scanning electron microscopy. For sample collection, biofilm organisms were washed from the glass beads, rinsed with PBS, and lyophilized to dryness. Planktonic organisms were collected from the supernatant of the biofilm chamber, rinsed with PBS, and lyophilized to dryness. The lyophilized samples were initially mixed 1:1 based on dry weight. Proteolytic peptides from this 1:1 sample were generated as described above, and subsequently analyzed using LC-MS. The bias factor feature of Protein Pilot, which measures how accurate the sample mixing is to $1: 1$, when all peptides containing isoleucine are compared, was utilized to determine how close to a 1:1 protein mix was actually obtained. The derived bias factor from this initial dataset was 0.57 (biofilm:planktonic), indicating that our samples contained twice as much proteins from the planktonic organisms than from the biofilm. This disproportionate mixing was expected as it is known that biofilm organisms generate an extracellular matrix which the planktonic organisms do not make. Therefore, in subsequent experiments we mixed the samples 2:1 (biofilm:planktonic) by weight, to yield a more comparable level of proteins between the two states.

To determine the efficiency of the label incorporation into the biofilm samples, equivalent amounts of biofilm and planktonic samples were separated by 1-D SDS-PAGE, individual bands extracted, trypsin digestion performed, and the samples analyzed by MALDI-TOF. The ${ }^{13} \mathrm{C}_{6}$ isoleucine utilized to label the biofilm organisms was purported by the manufacturer to have $98 \%$ labeling efficiency. The isotopic distributions from two representative isoleucine-containing peptides from two different proteins were used to determine incorporation efficiency. The peak intensities from 10 different spectra, of each peptide, were averaged and compared to MS-Isotope's (Protein Prospector web-based tool, University of California, San Francisco Mass Spectrometry Facility) predicted isotopic distribution of the peptide. These data showed that the predicted incorporation of the "heavy" isoleucine was $97.5 \%$. These data demonstrated that the ${ }^{13} \mathrm{C}_{6^{-}}$ Ile was properly and efficiently incorporated into the biofilm proteins. In addition, peptides without isoleucine showed no evidence of altered isotopic composition, demonstrating that the label had not been catabolized into other amino acids.

\section{LC-ESI-MS/MS data}

To reduce the complexity of the mixed samples and increase coverage, three extracts were generated based on protein solubility (Figure 2). Each extract was briefly separated by SDS-PAGE, and then an in-gel trypsin digest was performed. Samples were prepared from three biological replicates and were analyzed by nano-LC-ESI MS/MS. Injection replicates were run for all samples. All of the data generated from a biological replicate was searched using Protein Pilot, which also determined the bias factor for each experiment. As stated previously, a perfect 1:1 mix of the "heavy" and "light" samples would generate a bias factor of 1 . Protein Pilot determined that our experiments had bias factors of $0.986,1.2277$, and 1.0219 in biological replicates 1,2 , and 3 respectively. These data showed that we had achieved a reasonable mix of our biofilm and planktonic populations in each of the biological replicates, an important parameter for efficient matching and accurate quantitation of peptides from the two groups. 
Overall 814 unique proteins were identified with 99\% confidence and at least two peptides at 95\% confidence, corresponding to $\sim 45 \%$ of the total proteome (Additional file 1). In biological replicate one, 721 proteins were identified with 99\% confidence and at least two peptides at 95\% confidence (Additional file 2). Of these proteins, 33 proteins showed an upward trend in the biofilm samples while 35 proteins showed evidence of downregulation (Additional files 3 and 4). For biological replicate two, 723 proteins were identified with $99 \%$ confidence and at least two peptides at 95\% confidence (Additional file 5), of these 11 appeared to be upregulated in the biofilm and 13 downregulated (Additional files 6 and 7). 668 proteins were identified with $99 \%$ confidence and at least two peptides at $95 \%$ confidence in biological replicate three (Additional file 8), with 21 proteins identified as being upregulated and 43 downregulated in the biofilm (Additional files 9 and 10). Comparison of the data from the three different biological replicates showed that 127 unique proteins were differentially expressed in the biofilm versus planktonic organisms (Table 1), corresponding to $\sim 7 \%$ of the total proteome. Two proteins were found to be differentially expressed in all three biological replicates, while four were common between replicates $\# 1$ and $\# 2$, and twenty-three proteins were common between experiments \#1 and \#3. Four differentially expressed proteins were found to be in common between experiments \#2 and \#3. In total, we observed 27 proteins that were consistently up or down-regulated between two or more biological replicates (Table 1), and five proteins that showed conflicting trends between two biological replicates and were therefore not investigated further (Additional file 11).

When the functional roles of the 127 proteins that showed differential expression between the biofilm samples and the planktonic organisms were examined, a number of key processes were identified (Figure 3). A trend towards downregulation was seen in proteins involved in energy metabolism, protein synthesis, and purine, pyrimidine, nucleoside, and nucleotide processes. Analysis of the data showed that $76 \%$ of the proteins (19/25 proteins) involved in energy metabolism showed a downward trend in the biofilm population. Further metabolic pathway analysis was performed on the proteins involved in energy metabolism using the KEGG website [45]. These analyses showed that a number of these proteins could be mapped to the pyruvate metabolism, glycolysis and pentose phosphate pathways (Additional files 12,13 and 14). These data also showed that $71 \%(17 / 24$ proteins) of the proteins involved in protein synthesis and identified as having differential protein expression were downregulated. All six of the proteins classified as being involved in purine, pyrimidine, nucleoside, and nucleotide processes, which were identified as being differential expressed in this study, showed a trend towards downregulation. Conversely, proteins involved in transcription, DNA metabolism, and fatty acid and phospholipid metabolism appeared to have an increased expression level in the biofilm. 83.3\% (5/6) of the proteins identified as being involved in transcription were upregulated in the biofilm. All three of the proteins classified in fatty acid and phospholipid metabolism showed higher expression levels in the biofilm bacteria than the planktonic organisms. $87.5 \%$ or $7 / 8$ of the proteins classified as DNA metabolism proteins were upregulated in the biofilm bacteria.

\section{LC-SRM/MS data}

To obtain better sensitivity and accuracy in the relative quantitation of some of the more important proteins identified in the global SILAC analysis, SRM-MS was performed. Proteins were selected from the list of differentially expressed proteins observed in the ESI-MS/MS analyses; additionally proteins of potential biological significance were also targeted in these analyses. Peptides observed from this set of proteins were refined to include only peptides which contained no methionine or cysteine residues, no missed cleavages, no $\mathrm{N}$-terminal glutamine or glutamic acid, and no adjacent tryptic sites. Nineteen proteins with at least one peptide which met the above criteria were analyzed by SRM-MS to examine whether the biofilm and planktonic samples were differentially expressed. Data for both the "heavy" and "light" populations was collected for 54 of the targeted 61 peptides (Additional file 15). Figure 4, Table 2, and Additional file 16 show the data from 10 of the 19 proteins that we obtained consistent quantitative results to those observed in our initial Protein Pilot analysis of the MS/MS data. The 9 remaining proteins had data that was either inconclusive or was inconsistent with our initial MS/MS dataset and thus were not confirmed by SRM analyses. Of the 10 proteins that were confirmed by SRM analyses, four showed downregulation and six showed upregulation in the biofilm samples compared to the planktonic samples, with all six of the upregulated proteins showing an average peptide ratio of $>1.5$ and one of the downregulated proteins showing an average peptide ratio of $<0.66$. The cysteinyl-tRNA synthetase protein, aerobic respiration control protein ArcA, the predicted regulator of cell mophogenesis and NO signaling protein, and the molybdate-binding periplasmic protein were all seen as downregulated in the biofilm. The NAD nucleotidase protein, the heme-binding protein $\mathrm{A}$, the glutamine synthetase protein, the protective surface antigen D15 protein, the probable acyl carrier protein phosphodiesterase, and the DNA gyrase protein subunit A were all found by SRM to be upregulated in the biofilm. One to five distinct peptides were used to target each protein in our multiplexed SRM-MS assays (Additional file 16). Of all of the proteins quantified by SRM, the aerobic respiration 
Table 1 Proteins Predicted to be up- or downregulated, by Protein Pilot, with $\mathrm{p}$ values $\leq 0.05$

\begin{tabular}{|c|c|c|c|c|c|}
\hline \multirow[b]{2}{*}{ Accession \# } & \multirow[b]{2}{*}{ Protein name } & \multicolumn{3}{|c|}{ 'Biofilm: Planktonic ratio } & \multirow[b]{2}{*}{${ }^{2}$ Localization } \\
\hline & & Rep. 1 & Rep. 2 & Rep. 3 & \\
\hline \multicolumn{6}{|c|}{ Amino acid biosynthesis } \\
\hline AAX87912.1 & glutamine synthetase, GlnA & 1.71 & & 1.88 & Cytoplasmic \\
\hline AAX87713.1 & ketol-acid reductoisomerase, IIvC & & & 1.26 & Cytoplasmic \\
\hline AAX87519.1 & D-3-phosphoglycerate dehydrogenase, SerA & & & 0.54 & Cytoplasmic \\
\hline AAX87314.1 & dihydrodipicolinate synthase, DapA & 0.66 & & & Cytoplasmic \\
\hline \multicolumn{6}{|c|}{ Biosynthesis of cofactors, prosthetic groups, and carriers } \\
\hline AAX87263.1 & NAD nucleotidase, NadN & 2.47 & 1.62 & 1.23 & Periplasmic \\
\hline AAX87920.1 & octaprenyl-diphosphate synthase, IspB & & & 0.71 & Cytoplasmic \\
\hline AAX87900.1 & putative heme iron utilization protein & & & 0.82 & Cytoplasmic \\
\hline \multicolumn{6}{|c|}{ Cell envelope } \\
\hline AAX88031.1 & transferrin-binding protein 1, Tbp1 & 1.86 & & & OMP \\
\hline AAX87746.1 & VacJ lipoprotein & 1.58 & & & OMP \\
\hline AAX87040.1 & rod shape-determining protein MreB & 1.41 & & & Cytoplasmic \\
\hline AAX88649.1 & acylneuraminate cytidylyltransferase, SiaB & & & 0.70 & Cytoplasmic \\
\hline AAX88164.1 & Outer membrane protein P5 & & 0.58 & & OMP \\
\hline \multicolumn{6}{|c|}{ Cellular processes } \\
\hline AAX88712.1 & predicted periplasmic or secreted lipoprotein & 1.57 & & & Periplasmic \\
\hline AAX87955.1 & protective surface antigen D15 & 1.44 & & & OMP \\
\hline AAX88561.1 & cell division protein MukB & 1.18 & & & Unknown \\
\hline AAX88143.1 & cell division protein FtsA & & 0.76 & & Cytoplasmic \\
\hline AAX87967.1 & catalase, HktE & 0.76 & & & Periplasmic \\
\hline \multicolumn{6}{|c|}{ Central intermediary metabolism } \\
\hline AAX87206.1 & $\begin{array}{l}\text { putative sialic acid transporter, TRAP-type C4-dicarboxylate } \\
\text { transport system, periplasmic component. SiaP }\end{array}$ & 0.67 & & 0.63 & Periplasmic \\
\hline
\end{tabular}

\section{DNA metabolism}

$\begin{array}{ll}\text { AAX87735.1 } & \text { DNA mismatch repair protein MutS } \\ \text { AAX88107.1 } & \text { DNA ligase, LigN } \\ \text { AAX88664.1 } & \text { transcription-repair coupling factor, Mfd } \\ \text { AAX88280.1 } & \text { DNA-binding protein H-NS homolog } \\ \text { AAX88572.1 } & \text { DNA topoisomerase I, TopA } \\ \text { AAX87482.1 } & \text { DNA-binding protein HU } \\ \text { AAX87308.1 } & \text { UvrABC system protein A } \\ \text { AAX88029.1 } & \text { DNA polymerase III, beta chain, DnaN } \\ \text { Energy metabolism } \\ \text { AAX87718.1 } & \text { glycerophosphoryl diester phosphodiesterase precursor, Glp } \\ \text { AAX88650.1 } & \text { putative NAD(P)H nitroreductase, NsfB } \\ \text { AAX87025.1 } & \text { Citrate lyase alpha chain, citF } \\ \text { AAX88575.1 } & \text { NAD(P) transhydrogenase subunit alpha, PntA } \\ \text { AAX88675.1 } & \text { NADP-dependent malic enzyme, Mao2 } \\ \text { AAX88704.1 } & \text { D-lactate dehydrogenase, Dld } \\ \text { AAX88019.1 } & \text { 6-phosphofructokinase, PfkA } \\ \text { AAX87882.1 } & \text { fumarate reductase flavoprotein subunit, FrdA } \\ \text { AAX88128.1 } & \text { transaldolase, TalB }\end{array}$


Table 1 Proteins Predicted to be up- or downregulated, by Protein Pilot, with p values $\leq 0.05$ (Continued)

\begin{tabular}{|c|c|c|c|c|c|}
\hline AAX87573.1 & fructose-bisphosphate aldolase, Fba & 0.73 & & 0.55 & Cytoplasmic \\
\hline AAX88202.1 & acetate kinase, AckA & 0.70 & & 0.55 & Cytoplasmic \\
\hline AAX88159.1 & thioredoxin reductase, $\operatorname{TrxB}$ & & & 0.56 & Cytoplasmic \\
\hline AAX87856.1 & phosphoenolpyruvate carboxykinase, PckA & & & 0.57 & Cytoplasmic \\
\hline AAX88535.1 & fumarate hydratase class II, FumC & & & 0.59 & Cytoplasmic \\
\hline AAX87709.1 & triosephosphate isomerase, TpiA & & & 0.64 & Cytoplasmic \\
\hline AAX88580.1 & 1,4-alpha-glucan branching enzyme, GlgB & & & 0.66 & Cytoplasmic \\
\hline AAX88208.1 & malate dehydrogenase, Mdh & 0.66 & & & Unknown \\
\hline AAX87248.1 & flavodoxin, FldA & 0.68 & & & Cytoplasmic \\
\hline AAX87583.1 & aspartate ammonia-lyase, AspA & & & 0.70 & Cytoplasmic \\
\hline AAX87004.1 & glyceraldehyde 3-phosphate dehydrogenase, GapA & & 0.70 & 0.78 & Cytoplasmic \\
\hline AAX88293.1 & pyruvate kinase, PykA & & & 0.72 & Cytoplasmic \\
\hline AAX87574.1 & phosphoglycerate kinase, Pgk & 0.75 & & & Cytoplasmic \\
\hline AAX87971.1 & enolase, Eno & 0.77 & & 0.81 & Cytoplasmic \\
\hline AAX88160.1 & thioredoxin domain-containing protein, YbbN & & & 0.78 & Cytoplasmic \\
\hline AAX87237.1 & formate acetyltransferase, PflB & & & 0.79 & Cytoplasmic \\
\hline \multicolumn{6}{|c|}{ Fatty acid and phospholipid metabolism } \\
\hline AAX87797.1 & glycerol-3-phosphate acyltransferase, PlsB & 1.50 & & & Cyto. Memb. \\
\hline AAX87445.1 & long-chain-fatty-acid-CoA ligase, LcfA & 1.60 & & & Cyto. Memb. \\
\hline AAX88571.1 & probable acyl carrier protein phosphodiesterase, AcpD & 1.50 & & & Cytoplasmic \\
\hline \multicolumn{6}{|c|}{ Hypothetical proteins } \\
\hline AAX87451.1 & conserved hypothetical cupin superfamily metalloenzyme & & 1.36 & & Cytoplasmic \\
\hline AAX88259.1 & conserved hypothetical phosphate transport regulator & & & 0.65 & Cytoplasmic \\
\hline AAX87425.1 & conserved hypothetical protein & & 0.73 & & Unknown \\
\hline AAX88050.1 & conserved hypothetical protein & 0.80 & & & Cytoplasmic \\
\hline \multicolumn{6}{|l|}{ Protein fate } \\
\hline AAX87914.1 & peptidase B, pepB & & & 1.52 & Cytoplasmic \\
\hline AAX87592.1 & 60 kDa chaperonin, GroEL & & & 1.52 & Cytoplasmic \\
\hline AAX87863.1 & Xaa-Pro aminopeptidase, PepP & & & 1.51 & Cytoplasmic \\
\hline AAX88683.1 & chaperone protein DnaK & & & 1.42 & Cytoplasmic \\
\hline AAX87793.1 & protein-export protein SecB & & 1.41 & & Cytoplasmic \\
\hline AAX87272.1 & oligopeptidase A, PrlC & 1.37 & 1.28 & & Cytoplasmic \\
\hline AAX87706.1 & aminoacyl-histidine dipeptidase, PepD & 1.32 & & & Cytoplasmic \\
\hline AAX87591.1 & 10 kDa chaperonin, GroES & 0.42 & & & Cytoplasmic \\
\hline AAX87652.1 & peptidase E, PepE & 0.52 & & & Cytoplasmic \\
\hline AAX87816.1 & cell division protein FtsY & & & 0.56 & Cytoplasmic \\
\hline AAX88211.1 & thiol:disulfide interchange protein DsbC & 0.58 & & & Periplasmic \\
\hline AAX87741.1 & trigger factor, Tig & & & 0.64 & Cytoplasmic \\
\hline AAX88760.1 & cytosol aminopeptidase, PepA & & & 0.72 & Cytoplasmic \\
\hline \multicolumn{6}{|c|}{ Protein synthesis } \\
\hline AAX88424.1 & phenylalanyl-tRNA synthetase beta chain, PheT & & & 2.11 & Cytoplasmic \\
\hline AAX87782.1 & prolyl-tRNA synthetase, ProS & & & 2.00 & Cytoplasmic \\
\hline AAX87660.1 & 30 S ribosomal protein S7, RpsG & & & 1.81 & Cytoplasmic \\
\hline AAX87825.1 & $50 S$ ribosomal protein $\mathrm{L} 3, \mathrm{RplC}$ & & & 1.53 & Cytoplasmic \\
\hline AAX87593.1 & 50 S ribosomal protein $L 9$, Rpll & & 1.31 & & Cytoplasmic \\
\hline
\end{tabular}


Table 1 Proteins Predicted to be up- or downregulated, by Protein Pilot, with p values $\leq \mathbf{0 . 0 5}$ (Continued)

\begin{tabular}{|c|c|c|c|c|c|}
\hline AAX88652.1 & methionyl-tRNA synthetase, MetG & & 1.29 & & Cytoplasmic \\
\hline AAX87177.1 & Seryl-tRNA synthetase, SerS & & 1.25 & & Cytoplasmic \\
\hline AAX87580.1 & 30 S ribosomal protein S21, RpsU & 0.49 & & & Cytoplasmic \\
\hline AAX87839.1 & 30 S ribosomal protein S14, RpsN & 0.47 & & & Cytoplasmic \\
\hline AAX87952.1 & elongation factor Ts & 0.59 & & 0.58 & Cytoplasmic \\
\hline AAX87661.1 & elongation factor G, FusA & 0.61 & & 0.76 & Cytoplasmic \\
\hline AAX87855.1 & ribosome recycling factor, Frr & 0.68 & 0.73 & 0.62 & Cytoplasmic \\
\hline AAX87080.1 & cysteinyl-tRNA synthetase, CysS & 0.62 & & & Cytoplasmic \\
\hline AAX88252.1 & tyrosyl-tRNA synthetase, Tyrs & & & 0.63 & Cytoplasmic \\
\hline AAX87851.1 & 50 S ribosomal protein L17, RplQ & 0.66 & & & Cytoplasmic \\
\hline AAX87670.1 & $50 S$ ribosomal protein L10, RplJ & 0.67 & & & Cytoplasmic \\
\hline AAX87910.1 & GTP-binding protein TypA/ BipA & & & 0.68 & Cyto. Memb. \\
\hline AAX87836.1 & 50 S ribosomal protein L14, RpIN & & 0.71 & & Cytoplasmic \\
\hline AAX87838.1 & 50 S ribosomal protein $\mathrm{L} 5$, RplN & 0.74 & & & Cytoplasmic \\
\hline AAX88285.1 & arginyl-tRNA synthetase, ArgS & 0.74 & & & Cytoplasmic \\
\hline AAX87448.1 & predicted GTPase, probable translation factor & & & 0.74 & Cytoplasmic \\
\hline AAX87662.1 & elongation factor Tu, TufB & & 0.80 & 0.81 & Cytoplasmic \\
\hline AAX88543.1 & valyl-tRNA synthetase, ValS & & & 0.83 & Cytoplasmic \\
\hline AAX87376.1 & aspartyl-tRNA synthetase, AspS & & & 0.85 & Cytoplasmic \\
\hline \multicolumn{6}{|c|}{ Purines, pyrimidines, nucleosides, and nucleotides processes } \\
\hline AAX87406.1 & adenylate kinase, Adk & 0.55 & & 0.66 & Cytoplasmic \\
\hline AAX88253.1 & Ribose-phosphate pyrophosphokinase, PrsA & 0.57 & & 0.80 & Cytoplasmic \\
\hline AAX87655.1 & 2',3'-cyclic-nucleotide 2'-phosphodiesterase, CpdB & 0.78 & & 0.61 & Periplasmic \\
\hline AAX88085.1 & CTP synthase, PyrG & & 0.62 & & Cytoplasmic \\
\hline AAX87567.1 & Purine nucleoside phosphorylase, DeoD & & & 0.65 & Cytoplasmic \\
\hline AAX87928.1 & Serine hydroxymethyltransferase, GlyA & 0.75 & & & Cytoplasmic \\
\hline \multicolumn{6}{|c|}{ Regulatory functions } \\
\hline AAX87211.1 & $\mathrm{HflK}$ & 1.36 & & & Cytoplasmic \\
\hline AAX87210.1 & $\mathrm{HflC}$ & 1.22 & & & Cytoplasmic \\
\hline AAX87923.1 & aerobic respiration control protein ArcA & 0.37 & & 0.35 & Cytoplasmic \\
\hline \multicolumn{6}{|c|}{ Transcription } \\
\hline AAX88453.1 & transcription elongation factor GreA & 1.60 & & & Cytoplasmic \\
\hline AAX88611.1 & transcription elongation protein NusA & & & 1.44 & Cytoplasmic \\
\hline AAX87564.1 & DNA-directed RNA polymerase beta chain, RpoB & 1.17 & & 1.32 & Cytoplasmic \\
\hline AAX87290.1 & polyribonucleotide nucleotidyltransferase, Pnp & 1.17 & & 1.18 & Cytoplasmic \\
\hline AAX87467.1 & ribonuclease E, Rne & & & 1.14 & Cytoplasmic \\
\hline AAX87292.1 & Cold-shock DEAD-box protein A homolog, DeaD & & 0.52 & & Cytoplasmic \\
\hline \multicolumn{6}{|c|}{ Transport and binding proteins } \\
\hline AAX88593.1 & spermidine/putrescine-binding periplasmic protein 1 precursor, PotD1 & & & 2.04 & Periplasmic \\
\hline AAX88216.1 & putative L-lactate permease & 1.96 & & 1.68 & Cyto. Memb. \\
\hline AAX87899.1 & heme-binding protein $\mathrm{A}, \mathrm{HbpA}$ & 1.73 & & & Periplasmic \\
\hline AAX87717.1 & glycerol-3-phosphate transporter, GlpT & 1.50 & & & Cyto. Memb. \\
\hline AAX87322.1 & heme/hemopexin-binding protein $B, H x u B$ & 1.45 & & & OMP \\
\hline AAX88215.1 & heme utilization protein, Hup & 1.37 & & & OMP \\
\hline AAX88590.1 & spermidine/putrescine transport ATP-binding protein, PotA & & 1.34 & & Cyto. Memb. \\
\hline
\end{tabular}


Table 1 Proteins Predicted to be up- or downregulated, by Protein Pilot, with p values $\leq \mathbf{0 . 0 5}$ (Continued)

\begin{tabular}{|c|c|c|c|c|c|}
\hline AAX87417.1 & putative periplasmic chelated iron binding protein, $\mathrm{HfeA}$ & 1.31 & & & Periplasmic \\
\hline AAX88729.1 & predicted regulator of cell morphogenesis and NO signaling & 0.77 & & 0.39 & Cytoplasmic \\
\hline AAX88749.1 & molybdate-binding periplasmic protein, ModA & 0.46 & 0.69 & & Periplasmic \\
\hline AAX87869.1 & D-galactose-binding periplasmic protein precursor, MglB & 0.64 & & 0.59 & Periplasmic \\
\hline AAX88127.1 & periplasmic oligopeptide-binding protein, OppA & 0.71 & & 0.61 & Periplasmic \\
\hline AAX87555.1 & Ribose-binding periplasmic protein, RbsB & & 0.68 & & Periplasmic \\
\hline AAX88552.1 & phosphate-binding periplasmic protein precursor PstS & 0.72 & & 0.70 & Periplasmic \\
\hline AAX88551.1 & ferritin like protein 1 , FtnA & 0.77 & & & Cytoplasmic \\
\hline AAX87184.1 & high-affinity zinc uptake system protein ZnuA & 0.77 & & & Periplasmic \\
\hline AAX87223.1 & $\mathrm{Na}(+)$-translocating $\mathrm{NADH}$-quinone reductase subunit $\mathrm{A}$, NqrA & & 0.84 & & Cytoplasmic \\
\hline
\end{tabular}

${ }^{1}$ Bolded ratios show proteins predicted to be upregulated in the biofilm. Non-bolded ratios are proteins predicted to be downregulated in the biofilm.

${ }^{2}$ Localization determined using PSORTb program. OMP = outer membrane protein, Cyto. Memb. = cytoplasmic membrane protein.

control protein ArcA showed the highest level of downregulation in the biofilm and the NAD nucleotidase protein and the heme-binding protein A showed the highest levels of upregulation in the biofilm.

\section{Discussion}

In the current study, heavy-labeled isoleucine was metabolically incorporated into the biofilm of the isoleucine auxotroph, $H$. influenzae. Unlabeled planktonic organisms were mixed with those from the heavy-labeled biofilm cultures, three protein extracts were generated, digested with trypsin and analyzed by ESI-MS/MS. Database searches showed that a number of proteins had differential expression in the biofilm versus planktonic samples. A select group of these proteins was further evaluated by SRM-MS to verify our initial findings. The work presented here is the first quantitative comparison between the proteomes of $H$. influenzae biofilm and planktonic organisms using SILAC metabolic labeling. While there have been some previous proteomic studies of $H$. influenzae, these were limited to the identification of proteins in the extracellular matrix of biofilm populations (42) or to bacteria grown in

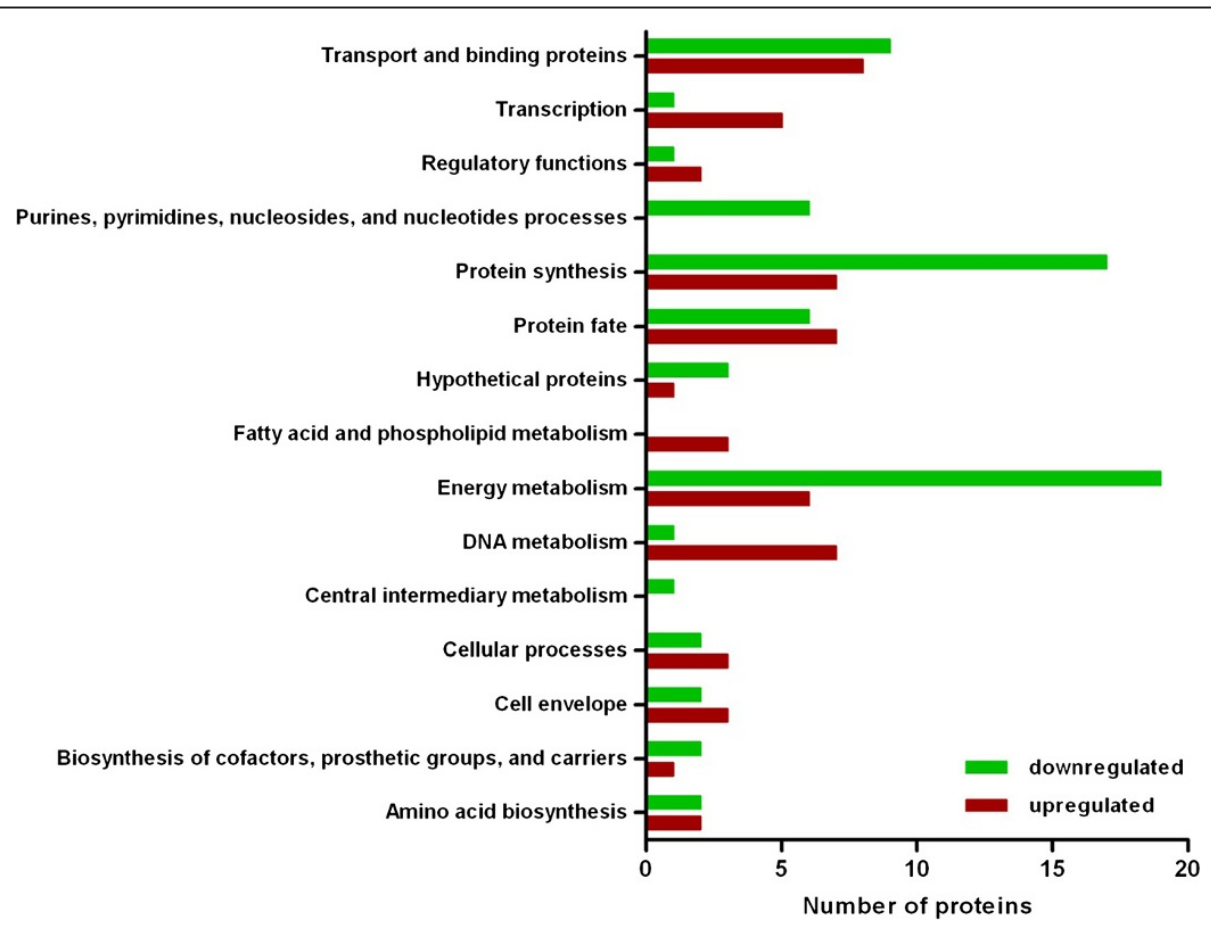

Figure 3 Plot of functional classifications of proteins predicted to be up- or downregulated in the biofilm compared to the planktonic organisms. The functional roles of the 127 proteins were determined using the role identification tool from the J. Craig Venter Institute Comprehensive Microbial Resource website (http://cmr.jcvi.org/cgi-bin/CMR/CmrHomePage.cgi) or the protein knowledgebase "(UniProtKB)" from the UniProt website (http://www.uniprot.org/). The proteins plotted had quantification ratios with $p$ values $\leq 0.05$. 


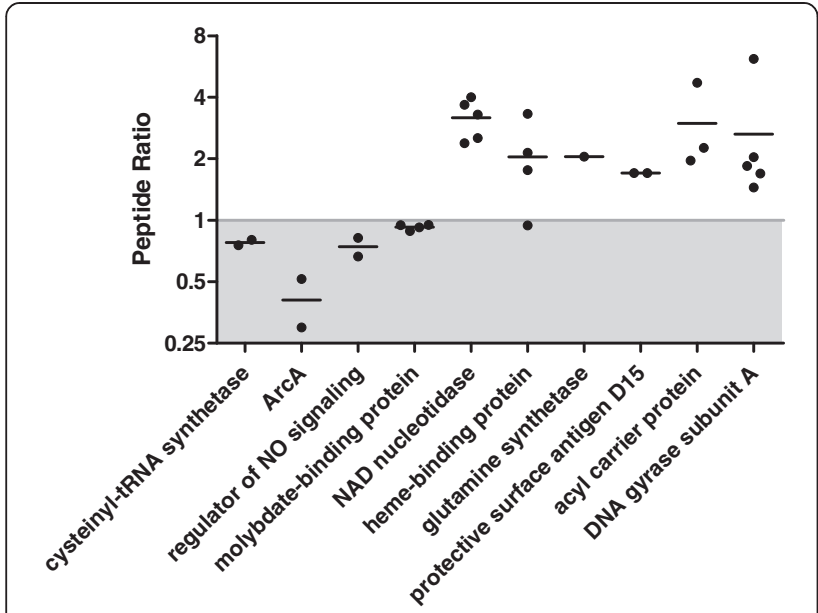

Figure 4 Log scale plots of the peptide ratios of the Biofilm: Planktonic (B:P) data observed in the SRM-MS analyses. Each dot represents the average of the B:P ratio for a distinct peptide. The line shows the overall average of the B:P data for each protein. Proteins whose average ratio showed downregulation in the biofilm appear in the grey shaded space of the plot. Proteins whose average ratio showed upregulation in the biofilm are plotted in the non-shaded area of the graph

human sputum [46]. In this latter study, Qu et al. identified thirty-one proteins with expression level ratios $>1.5$ in the sputum samples compared to organisms grown in defined media [46], many of these differentially expressed proteins were involved in stress response, anti-oxidant response, nutrient uptake, and adherence.

In the current study, SILAC labeling was used to compare the global proteomic profiles of planktonic and biofilm samples of $H$. influenzae to gain insight on how the

Table 2 Proteins shown by SRM to be have increased or decreased expression in the biofilm

\begin{tabular}{llr}
\hline Access. \# & Protein & 2 B:P \\
\hline AAX87080.1 & cysteinyl-tRNA synthetase & 0.78 \\
AAX87923.1 & aerobic respiration control protein ArCA & 0.39 \\
AAX88729.1 & $\begin{array}{l}\text { predicted regulator of cell morphogenesis } \\
\text { and NO signaling }\end{array}$ & 0.74 \\
AAX88749.1 & molybdate-binding periplasmic protein & 0.93
\end{tabular}

AAX87263.1 NAD nucleotidase

3.11

AAX87899.1 heme-binding protein A

1.85

AAX87912.1 glutamine synthetase

2.05

AAX87955.1 protective surface antigen D15

1.70

AAX88571.1 probable acyl carrier protein phosphodiesterase

AAX88658.1 DNA gyrase subunit A

${ }^{1}$ Non-bold proteins were found to have decreased expression in the biofilm, proteins shown in bold were found to have increased expression in the biofilm.

${ }^{2}$ Average of all of the peptide ratios of the biofilm (B): planktonic $(\mathrm{P})$ observed for the designated protein. organism remodels its proteome for these diverse growth conditions. This labeling strategy incorporated a heavy labeled amino acid metabolically into the biofilm population and allowed us to directly differentiate between the biofilm and planktonic proteins due to a mass shift in their corresponding peptides. The ability to differentiate between the two populations allowed the samples to be combined early in the sample work-flow, thus reducing variability that could arise from sample processing. Additionally, unlike the previous studies which utilized a single biological replicate $(42,43)$, we compared the biofilm and planktonic proteomes of three biological replicates. Using this approach, we identified 814 unique proteins with $99 \%$ confidence that had a minimum of two peptides. Of these proteins, 127 showed variable expression between the biofilm and planktonic samples, with 26 proteins showing a protein abundance change of $>1.5$ and 39 proteins showing a protein abundance change of $<0.66$ in at least one biological replicate. Of the differentially expressed proteins, biological replicates \#1 and \#3 showed good concordance with 23 proteins having the same trend in both replicates; while biological replicate \#2 did not correlate as well with the other two replicates, with 4 proteins showing similar trends in both cases. The overall number of proteins identified in biological replicate \#2 (731 proteins) corresponded well with replicates \#1 and \#3 (737 and 684 proteins, respectively). In addition, the bias factor, which represents how well the mix of the labeled and unlabeled samples are mixed, was 1.22 for biological replicate \#2 compared to 0.99 and 1.02 for biological replicates \#1 and $\# 3$, respectively. The similarity in the overall number of proteins identified and the bias factors for replicate \#2 compared to replicates \#1 and \#3 suggest that the differences seen in these replicates are not due to sample preparation. We believe the most likely explanation for the differences in the biofilm proteomic analyses of biological replicates \#1 and \#3 compared to replicate \#2 is due to phase variation of one or more genes.

Phase variation is described as a random process by which a clonal population of microbes can present heterogeneous phenotypes as a result of a reversible genetic event $[47,48]$. The process can involve several mechanisms, including slipped-strand mispairing (SSM), site-specific recombination, and epigenetic regulation mediated by DNA methylation [47]. SSM is a mechanism found in human pathogens, including pathogenic Neisseria, Bordetella pertussis, H. influenzae, and Helicobacter pylori. The resulting frame shift causes on-off changes in gene expression [49].

Among phase variable genes in NTHi, phase variation can occur every $5 \times 10^{-3}$ to $2 \times 10^{-4}$ colony forming units depending on the length of the polynucleotide repeat [49] and if this variant positively affects fitness it can become a predominant member of the population [50]. Thus, when single colonies are selected for in 
studies, these variants can be inadvertently selected for, thus biasing results. The sequenced NTHi genomes have at least 13 virulence related genes containing long nucleotide repeat sequences either within the open reading frames themselves or within promoter regions of genes [49-51]. During transcription of these long repeat regions by DNA polymerase loss or gain of a repeat unit results in putting the gene out of frame with premature termination of transcription [47,48]. Analysis of strain comparison data within a NTHi strain can be complicated by the fact that virulence-related phenotypes such as LOS structure, iron uptake, fimbriae and surface proteins are often subject to phase variation and these genes are important in biofilm formation [48]. As each of 13 or more phase-variable genes in each strain switches on and off in an independent fashion a single culture of NTHi might consist of a mixture of hundreds of different variants that differ in expression of a number of factors important in biofilm formation [2].

Previous studies have shown that growth within a biofilm is highly complex, with both actively growing cells as well as inactive cells depending on the position within the biofilm and the overall state of the biofilm [52]. Dispersal of the biofilm at various time-points has also been observed and most likely arises due to a number of factors such as nutrient depletion or the action of small molecules [53]. Also, despite the fact that in vitro biofilms appear to form distinct structures, evidence indicates that biofilm forming organisms do not possess comprehensive genetic programs for biofilm development [54]. Whether the variability seen in biological replicate \#2 is due to the biofilm undergoing changes due to phase variation, environmental factors or dispersal is unknown. It is clear however, that when the proteins that showed variable expression in any of the replicates were categorized by function and plotted (Figure 3), a small set of pathways seemed to show the most change. These groups, which showed the most changes, include proteins involved in DNA metabolism, energy metabolism and protein synthesis.

Proteins involved in DNA metabolism showed a general trend towards increased expression in the biofilm. These proteins include the DNA mismatch repair protein MutS, a transcription-repair coupling factor, protein A from the UvrABC system and the DNA-binding protein $\mathrm{HU}$, amongst others. All of these proteins have been implicated in either DNA repair or in protection against denaturation under environmental stress. It has been predicted that $H$. influenzae within a biofilm may be under oxidative stress, and this could cause DNA damage. In a microarray study comparing biofilm and planktonic cultures of NTHi by Pang and co-workers, transcripts for a number of factors involved in bacterial stress-response were reported to be upregulated in the biofilms [55]. One of these factors was a homolog of the DNA-binding protein associated with starvation (Dps). A $d p s$ mutant was generated in NTHi, and this mutant showed increased susceptibility to environmental stress and had reduced survival within a biofilm compared to the parent strain [55]. In a separate study, Gawnorski et al. used a genomic approach to investigate genes important in $H$. influenzae pathogenesis and also found that genes involved in DNA repair and oxidative stress were important for virulence in a murine pulmonary infection model [56]. In their study, they used a methodology designated HITS for "highthroughput insertion tracking by deep sequencing'. In this approach, transposon insertion libraries were generated and then sequenced either before or after passage in the murine lung model; the sequence outputs from before and after passage were then compared to determine genes important in pathogenesis. Their studies showed that the DNA repair genes $\operatorname{ruv} A, \operatorname{ruv} B, \operatorname{rec} R, \operatorname{rec} C, \operatorname{xer} C$ and $\operatorname{xer} D$ were all found to be necessary for virulence [56]. These studies also showed that the oxidative stress response genes $p g d X$ and $o x y R$ were necessary for a murine lung infection. Murphy et al. showed that the anti-oxidant enzyme, peroxiredoxin/glutaredoxin glutathione dependent peroxidase (PgdX), was expressed at higher levels in static biofilms compared to planktonic cultures [57]. This study also showed that COPD patient sera post-exacerbation had higher PgdX levels compared to paired patient sera pre-exacerbation [57]. The levels of PdgX were also shown to be elevated in $H$. influenzae grown in a sputum culture when compared to bacteria grown in a chemically defined media [46]. Unlike these previous studies, significant differences in PdgX levels of the biofilm compared to the planktonic bacteria were not detected in our study. This difference could be due to the growth state of our biofilm compared to the growth state of the samples from the previous studies. It is clear, however, that both in our study and in previous studies that the upregulation of DNA repair mechanisms is important for $H$. influenzae to cope with oxidative stress.

Energy metabolism and protein synthesis proteins were generally expressed at lower levels in the $H$. influenzae biofilm samples compared to the planktonic organisms. Although there is metabolic heterogeneity within the biofilm, reduced metabolism in bacterial biofilms is a generally accepted phenomenon [14,58]. The shift to a stationary or dormant phase within the biofilm seems to play an important role in antibiotic resistance $[14,58,59]$. For example, when Fux and colleagues evaluated Staphylococcus aureus biofilm "clumps", which had detached from the biofilm, they found that they were highly resistant to the antibiotic oxacillin [60]. This level of resistance was similar to stationary phase planktonic organisms grown in spent medium, suggesting a direct connection between metabolic activity and antibiotic resistance [60]. 
In a similar study, Anderl et al. showed that even though both ampicillin and ciprofloxacin were able to penetrate a Klebsiella pneumoniae biofilm, the organisms remained resistant to clearing by these drugs [61]. Planktonic bacteria, from stationary phase, grown in media lacking carbon and nitrogen sources, were similarly antibiotic resistant as the biofilm organisms [61]. When biofilm bacteria were dispersed into rich media they once again became susceptible to antibiotics [61]. These studies, as well as others, clearly demonstrate that reduced metabolism is not only a necessity due to nutrient limitation conditions, but that it is also likely a survival mechanism that allows the biofilm to escape clearance by antimicrobials. Our findings that both protein synthesis and metabolism decrease in the $H$. influenzae biofilm further strengthen the importance of these survival mechanisms.

The aerobic respiration control protein ArcA was found to be the most highly downregulated protein in our study. Our initial screen found that the biofilm: planktonic expression ratio of ArcA in two biological replicates was less than 0.37 . These results were further confirmed in our SRM studies, where two peptides were found to have an average biofilm:planktonic ratio of 0.39. $H$. influenzae encounters various levels of oxygen conditions both within the host and within biofilms; therefore, the bacteria has devised various mechanisms to cope with differing levels of oxygen availability. One such mechanism is ArcA [62-64]. This protein is part of a twocomponent regulatory system (ArcAB) that has been previously shown to be involved in modulating genes needed for adaptation to changes in respiration [62-64]. ArcA is thought to be most active under low oxygen conditions $[63,64]$. In E. coli ArcAB regulate genes involved in metabolic pathways, such as the TCA cycle, in response to respiratory conditions [65]. Similarly, ArcA was also found to modulate the expression level of genes involved in metabolic pathways in $H$. influenzae [64]. A recent metabolomics analysis of $H$. influenzae showed that the only TCA cycle enzymes present in $H$. influenzae are malate dehydrogenase, fumarate hydratase, succinyl CoA synthetase, and $\alpha$-ketoglutarate dehydrogenase [66]. Of these, both malate dehydrogenase and fumarate hydratase were found in our study to be downregulated in the biofilm. As Table 1 demonstrates, a number of proteins involved in respiration were also shown to be decreased in expression, including PfkA, FrdA, Fba, Eno, and PykA. Conversely, some proteins involved in this functional group were shown to be increased in expression, such as CitF, NsfB, Mao2, and Dld.

Biofilms are complex entities with evidence of stratified growth within their internal structures. One reason for this type of growth is in part due to the varying oxygen concentrations within a biofilm. Oxygen levels are higher near the surface, while oxygen levels near the base of the biofilm are most likely low. Indeed, Werner and co-workers used oxygen electrodes to show that oxygen only penetrated approximately $50 \mu \mathrm{m}$ into the biofilm [52]. These variations in oxygen levels within biofilms make respiration within a biofilm complex. Our data combined with previous studies suggest that some sections of the strata function at an aerobic level, while other sections of the biofilm operate in either microaerophilic or anaerobic environments. Adding to this complexity, ArcA was recently shown to regulate $d p s$ [64]. Dps has been shown to be important in dealing with oxidative stress resistance $[55,64]$. Since ArcA seems to be most active in low oxygen conditions, but paradoxically modulates genes important in coping with oxidative stress, it seems likely that ArcA and Dps may help the bacteria shift between low and high oxygen conditions.

The NAD nucleotidase protein NadN was found at higher levels in the biofilm organisms compared to the planktonic bacteria in all three biological replicates. SRM data further confirmed this with an average biofilm:planktonic ratio of 3:1. This ratio was determined from 4 peptides which were observed in all three biological replicates and one peptide that was observed in two biological replicates. The combination of the difference between the biofilm and planktonic levels being consistently observed amongst all three biological replicates as well as the high level of difference between NadN levels in the biofilm and planktonic conditions suggests that this protein is crucial in $H$. influenzae biofilm formation. It is known that $H$. influenzae lack most of the enzymes necessary for de novo synthesis of NAD; therefore, these bacteria have an absolute requirement for exogenous NAD (factor V). Previous studies have demonstrated that $\mathrm{NadN}$ is a periplasmic protein which functions as both an NAD pyrophosphatase and an NMN 5'-nucleotidase, and is necessary for growth on NAD in vitro $[67,68]$. Gawronski et al. showed that nadN was crucial for $H$. influenzae infection in a murine lung infection model [56]. Their studies also demonstrated the necessity of hel, which is also involved in NAD utilization, in their infection model [56]. It is clear that NAD utilization is crucial under a number of growth conditions. The increase in NadN levels in H. influenzae biofilms suggests that uptake and utilization of NAD is important in biofilm formation and/or maintenance.

In addition to $H$. influenzae's requirement of NAD for growth, these organisms also require heme. $H$. influenzae have developed a number of mechanisms for acquiring heme from the human host including heme binding proteins and heme utilization systems (for example: [69-77]). HbpA, was originally identified as being a heme binding protein $[71,75,78]$, but has subsequently been asserted to be primarily involved in glutathione acquisition [79]. The first identification of $H$. influenzae $\mathrm{HbpA}$ was achieved through transformation of an $H$. influenzae library into $E$. coli followed by screening for heme binding activity [78]. Morton et al. later showed that $\mathrm{HbpA}$ bound various forms of heme and hbpA mutants were unable to bind 
heme [75]. Morton and colleagues also showed that an hbpA mutant in a $H$. influenzae type B strain was reduced in its virulence in a 30 day old rat model of bacteremia [80]. More recently, Vergauwen and colleagues demonstrated that HbpA bound both reduced glutathione (GSH) and oxidized glutathione (GSSG) at physiologically relevant levels, while it only weakly bound hemin [79]. They proposed that glutathione is transported across the bacterial inner-membrane using an ATP-binding cassette (ABC)-like dipeptide transporter (DppBCDF), with HbpA as the periplasmic binding protein [79]. This group proposed to change the nomenclature of this protein from HbpA to GbpA (glutathione binding protein) [79]. In the present study, HbpA was found to be expressed at higher levels in the biofilm organisms compared to the planktonic bacteria. The reduced form of glutathione (GSH) is able to aid in the reduction of reactive oxygen species. If HbpA is truly a glutathione transporter, able to transport both GSH and GSSG, it is feasible that this protein may be important in assisting $H$. influenzae biofilm organisms with oxidative stress conditions. Conversely, if $\mathrm{HbpA}$ is primarily involved in acquiring heme, this protein most likely plays an important role in helping the biofilm organisms acquire iron from the host. Whether HbpA's primary role is binding heme, binding glutathione, or perhaps both, it is interesting to hypothesize that the promiscuity of HbpA's substrate binding may be by necessity or design and could play an important role in $H$. influenzae biofilm growth and virulence.

\section{Conclusions}

It is clear from the current study, as well as previous studies, that some common factors are important in biofilm formation. $H$. influenzae within a biofilm need ways of dealing with the various effects of oxidative stress and damage. The ability to obtain necessary growth factors, such as NAD and heme, are also crucial for survival. Biofilm organisms exist in a somewhat dormant state with reduced energy metabolism and reduced protein synthesis. It still remains unclear what bacterial factors, if any, regulate $H$. influenzae biofilm formation and maintenance. In the present study, we employed a SILAC metabolic labeling strategy to quantitatively compare the proteomes of the biofilm and planktonic states of NTHi. One of the major advantages of this approach over unlabeled strategies is the ability of the samples to be mixed early on in the processing steps. The key disadvantage of a comparative strategy is that it is not able to measure the absence of a protein in one condition compared to the other condition. Future strategies for evaluating the proteomes of these two growth conditions may be able to address this issue. In addition, large scale proteomic approaches typically miss comparisons of peptides with post-translational modifications (PTMs), as these peptides are usually a small percentage of the total peptide population. With the recent discoveries of a number of PTMs in bacteria [81], it seems reasonable to assume that PTMs will play at least some role in biofilm formation or maintenance. The data presented here, coupled with future studies, should provide a good foundation for potential drug therapy targets that could lead to more effective clearance of resistant NTHi biofilm organisms.

\section{Additional files}

Additional file 1: Total unique proteins $99 \%$ Conf and 2 peptides with $95 \%$ conf.

Additional file 2: Proteins identified with at least $99 \%$ confidence and at least two peptides with 95\% confidence in Replicate \#1.

Additional file 3: Proteins differentially expressed, with p-values $\leq$ 0.05 and EF <2, in Replicate \#1.

Additional file 4: Protein Pilot peptide summary of peptides used for quantitation of proteins whose $p$ value for $\mathrm{H}: \mathrm{L}$ ratio was $\leq 0.05$ in Replicate \#1.

Additional file 5: Proteins Identified with at least $99 \%$ Confidence and at least two peptides at $\mathbf{9 5 \%}$ confidence in Replicate \#2.

Additional file 6: Proteins differentially expressed, with $\mathrm{p}$-values $\leq$ 0.05 and EF <2, in Replicate \#2.

Additional file 7: Protein Pilot peptide summary of peptides used for quantitation of proteins whose $p$ value for $\mathrm{H}: \mathrm{L}$ ratio was $\leq 0.05$ for Replicate \#2.

Additional file 8: Proteins Identified with at least 99\% Confidence and at least two peptides at $95 \%$ confidence in Replicate \#3.

Additional file 9: Proteins differentially expressed, with $p$-values $\leq$ 0.05 and EF $<2$, in Replicate \#3.

Additional file 10: Protein Pilot peptide summary of peptides used for quantitation of proteins whose $\mathrm{p}$ value for $\mathrm{H}: \mathrm{L}$ ratio was $\leq 0.05$ for Replicate \#3.

Additional file 11: Proteins predicted, by Protein Pilot, to have variable up- or downregulation in the biofilm.

Additional file 12: The genes encoding proteins involved in pyruvate metabolism that were found to be differentially expressed in the biofilm: planktonic samples were plotted on KEGG pathways.

Additional file 13: The genes encoding proteins involved in glycolysis that were found to be differentially expressed in the biofilm:planktonic samples were plotted on KEGG pathways.

Additional file 14: The genes encoding proteins involved in the pentose phosphate pathway that were found to be differentially expressed in the biofilm:planktonic samples were plotted on KEGG pathways.

Additional file 15: Peptides targeted for SRM analyses.

Additional file 16: Proteins shown by SRM to be up- or downregulated.

\section{Abbreviations}

NTHi: Non-typeable Haemophilus influenzae; SILAC: Stable isotope labeling by amino acids in cell culture; LC-MS: Liquid chromatography-mass spectrometry; SRM-MS: Selected reaction monitoring-mass spectrometry; COPD: Chronic obstructive pulmonary disease; LOS: Lipooligosaccharide; MALDI-TOF: Matrix-assisted laser desorption ionization time-of-flight; ESI-MS: Electrospray ionization-mass spectrometry.

\section{Competing interests}

The authors declare that they have no competing interests. 


\section{Authors' contributions}

Experimental conception and design: DMBP, MAA and BWG. Performance of experiments and data processing: DMBP, MRK, JMH and AS. Interpretation of data: DMBP, JMH, NJP, MAA and BWG. Writing and editing of manuscript: DMBP, $J M H, N J P, M A A$ and BWG. All authors read and approved the final manuscript

\section{Acknowledgments}

The authors wish to thank Birgit Schilling for excellent technical assistance. This work was supported by National Institutes of Health Grant RO1 AI024616 (to MAA and BWG). Mass spectrometric instrumentation for this study was provided by the mass spectrometry core facility at the Buck Institute for Research on Aging and the shared instrumentation grants S10 RR024615 and S10 RR0279953 (to BWG).

\section{Author details}

${ }^{1}$ The Buck Institute for Research on Aging, Novato, CA 94945, USA. ${ }^{2}$ Washington University School of Medicine, St. Louis, MO 63110, USA. ${ }^{3}$ The University of lowa, lowa City, IA 52242, USA. ${ }^{4}$ The University of California San Francisco, San Francisco, CA 94143, USA.

Received: 15 September 2014 Accepted: 16 December 2014 Published online: 31 December 2014

\section{References}

1. Agrawal A, Murphy TF: Haemophilus influenzae infections in the $\mathrm{H}$. influenzae type b conjugate vaccine era. J Clin Microbiol 2011, 49(11):3728-3732.

2. Erwin AL, Smith AL: Nontypeable Haemophilus influenzae: understanding virulence and commensal behavior. Trends Microbiol 2007, 15(8):355-362.

3. Foxwell AR, Kyd JM, Cripps AW: Nontypeable Haemophilus influenzae: pathogenesis and prevention. Microbiol Mol Biol Rev 1998, 62(2):294-308.

4. Murphy TF, Faden H, Bakaletz LO, Kyd JM, Forsgren A, Campos J, Virji M, Pelton SI: Nontypeable Haemophilus influenzae as a pathogen in children. Pediatr Infect Dis J 2009, 28(1):43-48

5. Moghaddam SJ, Ochoa CE, Sethi S, Dickey BF: Nontypeable Haemophilus influenzae in chronic obstructive pulmonary disease and lung cancer. Int J Chron Obstruct Pulmon Dis 2011, 6:113-123.

6. Greiner LL, Watanabe H, Phillips NJ, Shao J, Morgan A, Zaleski A, Gibson BW, Apicella MA: Nontypeable Haemophilus influenzae strain 2019 produces a biofilm containing $\mathrm{N}$-acetylneuraminic acid that may mimic sialylated O-linked glycans. Infect Immun 2004, 72(7):4249-4260.

7. Hall-Stoodley L, Hu FZ, Gieseke A, Nistico L, Nguyen D, Hayes J, Forbes M, Greenberg DP, Dice B, Burrows A, Wackym PA, Stoodley P, Post JC, Ehrlich $G D$, Kerschner JE: Direct detection of bacterial biofilms on the middle-ear mucosa of children with chronic otitis media. JAMA 2006, 296(2):202-211.

8. Hong W, Mason K, Jurcisek J, Novotny L, Bakaletz LO, Swords WE: Phosphorylcholine decreases early inflammation and promotes the establishment of stable biofilm communities of nontypeable Haemophilus influenzae strain 86-028NP in a chinchilla model of otitis media. Infect Immun 2007, 75(2):958-965.

9. Hong W, Pang B, West-Barnette S, Swords WE: Phosphorylcholine expression by nontypeable Haemophilus influenzae correlates with maturation of biofilm communities in vitro and in vivo. J Bacteriol 2007, 189(22):8300-8307.

10. Jurcisek J, Greiner L, Watanabe H, Zaleski A, Apicella MA, Bakaletz LO: Role of sialic acid and complex carbohydrate biosynthesis in biofilm formation by nontypeable Haemophilus influenzae in the chinchilla middle ear. Infect Immun 2005, 73(6):3210-3218.

11. Murphy TF, Kirkham C: Biofilm formation by nontypeable Haemophilus influenzae: strain variability, outer membrane antigen expression and role of pili. BMC Microbiol 2002, 2:7

12. Swords WE, Moore ML, Godzicki L, Bukofzer G, Mitten MJ, VonCannon J: Sialylation of lipooligosaccharides promotes biofilm formation by nontypeable Haemophilus influenzae. Infect Immun 2004, 72(1):106-113.

13. Banat IM, De Rienzo MA, Quinn GA: Microbial biofilms: biosurfactants as antibiofilm agents. Appl Microbiol Biotechnol 2014, 98(24): 9915-29.

14. Fux CA, Costerton JW, Stewart PS, Stoodley P: Survival strategies of infectious biofilms. Trends Microbiol 2005, 13(1):34-40.

15. Hoiby N, Bjarnsholt T, Givskov M, Molin S, Ciofu O: Antibiotic resistance of bacterial biofilms. Int J Antimicrob Agents 2010, 35(4):322-332.
16. Seneviratne CJ, Wang Y, Jin L, Wong SS, Herath TD, Samaranayake LP: Unraveling the resistance of microbial biofilms: has proteomics been helpful? Proteomics 2012, 12(4-5):651-665

17. Bakaletz LO: Bacterial biofilms in otitis media: evidence and relevance. Pediatr Infect Dis J 2007, 26(10 Suppl):S17-S19.

18. Costerton W, Veeh R, Shirtliff M, Pasmore M, Post C, Ehrlich G: The application of biofilm science to the study and control of chronic bacterial infections. J Clin Invest 2003, 112(10):1466-1477.

19. Kyd JM, McGrath J, Krishnamurthy A: Mechanisms of bacterial resistance to antibiotics in infections of COPD patients. Curr Drug Targets 2011, 12(4):521-530.

20. Flemming HC, Wingender J: The biofilm matrix. Nat Rev Microbio/ 2010, 8(9):623-633.

21. Allen S, Zaleski A, Johnston JW, Gibson BW, Apicella MA: Novel sialic acid transporter of Haemophilus influenzae. Infect Immun 2005, 73(9):5291-5300.

22. Bakaletz LO, Baker BD, Jurcisek JA, Harrison A, Novotny LA, Bookwalter JE, Mungur R, Munson RS Jr: Demonstration of Type IV pilus expression and a twitching phenotype by Haemophilus influenzae. Infect Immun 2005, 73(3):1635-1643

23. Carruthers MD, Tracy EN, Dickson AC, Ganser KB, Munson RS Jr, Bakaletz LO Biological roles of nontypeable Haemophilus influenzae type IV pilus proteins encoded by the pil and com operons. J Bacteriol 2012, 194(8):1927-1933.

24. Izano EA, Shah SM, Kaplan JB: Intercellular adhesion and biocide resistance in nontypeable Haemophilus influenzae biofilms. Microb Pathog 2009, 46(4):207-213.

25. Jurcisek JA, Bakaletz LO: Biofilms formed by nontypeable Haemophilus influenzae in vivo contain both double-stranded DNA and type IV pilin protein. J Bacterio/ 2007, 189(10):3868-3875.

26. Lanucara F, Eyers CE: Mass spectrometric-based quantitative proteomics using SILAC. Methods Enzymol 2011, 500:133-150.

27. Ong SE, Blagoev B, Kratchmarova I, Kristensen DB, Steen H, Pandey A, Mann $\mathrm{M}$ : Stable isotope labeling by amino acids in cell culture, SILAC, as a simple and accurate approach to expression proteomics. Mol Cell Proteomics 2002, 1(5):376-386.

28. Ong SE, Mann M: Mass spectrometry-based proteomics turns quantitative. Nat Chem Biol 2005, 1(5):252-262.

29. Dreisbach A, Otto A, Becher D, Hammer E, Teumer A, Gouw JW, Hecker M, Volker $U$ : Monitoring of changes in the membrane proteome during stationary phase adaptation of Bacillus subtilis using in vivo labeling techniques. Proteomics 2008, 8(10):2062-2076.

30. Phillips NJ, Steichen CT, Schilling B, Post DM, Niles RK, Bair TB, Falsetta ML, Apicella MA, Gibson BW: Proteomic analysis of Neisseria gonorrhoeae biofilms shows shift to anaerobic respiration and changes in nutrient transport and outermembrane proteins. PLoS One 2012, 7(6):e38303.

31. Ruiz L, Coute Y, Sanchez B, de los Reyes-Gavilan CG, Sanchez JC, Margolles $A$ : The cell-envelope proteome of Bifidobacterium longum in an in vitro bile environment. Microbiology 2009, 155(Pt 3):957-967.

32. Soufi B, Kumar C, Gnad F, Mann M, Mijakovic I, Macek B: Stable isotope labeling by amino acids in cell culture (SILAC) applied to quantitative proteomics of Bacillus subtilis. J Proteome Res 2010, 9(7):3638-3646.

33. Yu JL, Guo L: Quantitative proteomic analysis of Salmonella enterica serovar Typhimurium under PhoP/PhoQ activation conditions. J Proteome Res 2011, 10(7):2992-3002.

34. Campagnari AA, Gupta MR, Dudas KC, Murphy TF, Apicella MA: Antigenic diversity of lipooligosaccharides of nontypable Haemophilus influenzae. Infect Immun 1987, 55(4):882-887.

35. Whiteley M, Bangera MG, Bumgarner RE, Parsek MR, Teitzel GM, Lory S, Greenberg EP: Gene expression in Pseudomonas aeruginosa biofilms. Nature 2001, 413(6858):860-864.

36. Shilov IV, Seymour SL, Patel AA, Loboda A, Tang WH, Keating SP, Hunter CL, Nuwaysir LM, Schaeffer DA: The Paragon Algorithm, a next generation search engine that uses sequence temperature values and feature probabilities to identify peptides from tandem mass spectra. Mol Cell Proteomics 2007, 6(9):1638-1655.

37. Harrison A, Dyer DW, Gillaspy A, Ray WC, Mungur R, Carson MB, Zhong H, Gipson J, Gipson M, Johnson LS, Lewis L, Bakaletz LO, Munson RS Jr: Genomic sequence of an otitis media isolate of nontypeable Haemophilus influenzae: comparative study with $\mathrm{H}$. influenzae serotype d, strain KW20. J Bacteriol 2005, 187(13):4627-4636.

38. Tang WH, Shilov IV, Seymour SL: Nonlinear fitting method for determining local false discovery rates from decoy database searches. J Proteome Res 2008, 7(9):3661-3667. 
39. J. Craig Venter Institute Comprehensive Microbial Resource. http://cmr.jcvi.org/cgi-bin/CMR/CmrHomePage.cgi

40. Protein knowledgebase (UniProtKB). http://www.uniprot.org/

41. Yu NY, Wagner JR, Laird MR, Melli G, Rey S, Lo R, Dao P, Sahinalp SC, Ester M, Foster L, Brinkman FS: PSORTb 3.0: improved protein subcellular localization prediction with refined localization subcategories and predictive capabilities for all prokaryotes. Bioinformatics 2010, 26 (13):1608-1615.

42. Maclean B, Tomazela DM, Abbatiello SE, Zhang S, Whiteaker JR, Paulovich $A G$, Carr SA, Maccoss MJ: Effect of collision energy optimization on the measurement of peptides by selected reaction monitoring (SRM) mass spectrometry. Anal Chem 2010, 82(24):10116-10124.

43. MacLean B, Tomazela DM, Shulman N, Chambers M, Finney GL, Frewen B, Kern R, Tabb DL, Liebler DC, MacCoss MJ: Skyline: an open source document editor for creating and analyzing targeted proteomics experiments. Bioinformatics 2010, 26(7):966-968.

44. Post D, JM Held, MR Ketterer, NJ Phillips, A Sahu, MA Apicella, and BW Gibson: Haemophilus influezae proteomics data from unlabeled planktonic and metabolically labeled biofilm samples. massIVE ftp site ftp://MSV000078838@massive.ucsd.edu.

45. KEGG website. http://www.genome.jp/kegg/

46. Qu J, Lesse AJ, Brauer AL, Cao J, Gill SR, Murphy TF: Proteomic expression profiling of Haemophilus influenzae grown in pooled human sputum from adults with chronic obstructive pulmonary disease reveal antioxidant and stress responses. BMC Microbiol 2010, 10:162.

47. van der Woude MW: Phase variation: how to create and coordinate population diversity. Curr Opin Microbiol 2011, 14(2):205-211.

48. Weiser JN: The generation of diversity by Haemophilus influenzae. Trends Microbiol 2000, 8(10):433-435.

49. De Bolle X, Bayliss CD, Field D, van de Ven T, Saunders NJ, Hood DW, Moxon ER: The length of a tetranucleotide repeat tract in Haemophilus influenzae determines the phase variation rate of a gene with homology to type III DNA methyltransferases. Mol Microbiol 2000, 35(1):211-222

50. Poole J, Foster E, Chaloner K, Hunt J, Jennings MP, Bair T, Knudtson K, Christensen E, Munson RS Jr, Winokur PL, Apicella MA: Analysis of nontypeable haemophilus influenzae phase-variable genes during experimental human nasopharyngeal colonization. J Infect Dis 2013, 208(5):720-727.

51. van Ham SM, van Alphen L, Mooi FR, van Putten JP: Phase variation of $H$. influenzae fimbriae: transcriptional control of two divergent genes through a variable combined promoter region. Cell 1993, 73(6):1187-1196.

52. Werner E, Roe F, Bugnicourt A, Franklin MJ, Heydorn A, Molin S, Pitts B, Stewart PS: Stratified growth in Pseudomonas aeruginosa biofilms. Appl Environ Microbiol 2004, 70(10):6188-6196.

53. Oppenheimer-Shaanan Y, Steinberg N, Kolodkin-Gal I: Small molecules are natural triggers for the disassembly of biofilms. Trends Microbiol 2013, 21(11):594-601.

54. Klausen M, Gjermansen M, Kreft JU, Tolker-Nielsen T: Dynamics of development and dispersal in sessile microbial communities: examples from Pseudomonas aeruginosa and Pseudomonas putida model biofilms. FEMS Microbiol Lett 2006, 261(1):1-11.

55. Pang B, Hong W, Kock ND, Swords WE: Dps promotes survival of nontypeable Haemophilus influenzae in biofilm communities in vitro and resistance to clearance in vivo. Front Cell Infect Microbiol 2012, 2:58

56. Gawronski JD, Wong SM, Giannoukos G, Ward DV, Akerley BJ: Tracking insertion mutants within libraries by deep sequencing and a genomewide screen for Haemophilus genes required in the lung. Proc Natl Acad Sci U S A 2009, 106(38):16422-16427.

57. Murphy TF, Kirkham C, Sethi S, Lesse AJ: Expression of a peroxiredoxinglutaredoxin by Haemophilus influenzae in biofilms and during human respiratory tract infection. FEMS Immunol Med Microbiol 2005, 44(1):81-89.

58. Hall-Stoodley L, Stoodley P: Evolving concepts in biofilm infections. Cell Microbiol 2009, 11(7):1034-1043.

59. Martinez JL, Rojo F: Metabolic regulation of antibiotic resistance. FEMS Microbiol Rev 2011, 35(5):768-789.

60. Fux CA, Wilson S, Stoodley P: Detachment characteristics and oxacillin resistance of Staphyloccocus aureus biofilm emboli in an in vitro catheter infection model. J Bacteriol 2004, 186(14):4486-4491.

61. Anderl JN, Zahller J, Roe F, Stewart PS: Role of nutrient limitation and stationaryphase existence in Klebsiella pneumoniae biofilm resistance to ampicillin and ciprofloxacin. Antimicrob Agents Chemother 2003, 47(4):1251-1256.
62. De Souza-Hart JA, Blackstock W, Di Modugno V, Holland IB, Kok M: Twocomponent systems in Haemophilus influenzae: a regulatory role for ArcA in serum resistance. Infect Immun 2003, 71(1):163-172.

63. Georgellis D, Kwon O, Lin EC, Wong SM, Akerley BJ: Redox signal transduction by the ArcB sensor kinase of Haemophilus influenzae lacking the PAS domain. J Bacterio/ 2001, 183(24):7206-7212.

64. Wong SM, Alugupalli KR, Ram S, Akerley BJ: The ArcA regulon and oxidative stress resistance in Haemophilus influenzae. Mol Microbiol 2007, 64(5):1375-1390.

65. Lynch AS, Lin ECC (Eds): Responses to molecular oxygen. Washington: DC ASM Press; 1996

66. Othman DS, Schirra H, McEwan AG, Kappler U: Metabolic versatility in Haemophilus influenzae: a metabolomic and genomic analysis. Front Microbiol 2014, 5:69.

67. Kemmer G, Reilly TJ, Schmidt-Brauns J, Zlotnik GW, Green BA, Fiske MJ, Herbert $M$, Kraiss A, Schlor S, Smith A, Reidl J: NadN and e (P4) are essential for utilization of NAD and nicotinamide mononucleotide but not nicotinamide riboside in Haemophilus influenzae. J Bacteriol 2001, 183(13):3974-3981.

68. Reidl J, Schlor S, Kraiss A, Schmidt-Brauns J, Kemmer G, Soleva E: NADP and NAD utilization in Haemophilus influenzae. Mol Microbiol 2000, 35(6):1573-1581.

69. Mason KM, Raffel FK, Ray WC, Bakaletz LO: Heme utilization by nontypeable Haemophilus influenzae is essential and dependent on Sap transporter function. J Bacteriol 2011, 193(10):2527-2535.

70. Cope LD, Thomas SE, Latimer JL, Slaughter CA, Muller-Eberhard U, Hansen EJ: The $100 \mathrm{kDa}$ haem:haemopexin-binding protein of Haemophilus influenzae: structure and localization. Mol Microbiol 1994, 13(5):863-873.

71. Hanson MS, Slaughter C, Hansen EJ: The hbpA gene of Haemophilus influenzae type $b$ encodes a heme-binding lipoprotein conserved among heme-dependent Haemophilus species. Infect Immun 1992, 60(6):2257-2266.

72. Jarosik GP, Sanders JD, Cope LD, Muller-Eberhard U, Hansen EJ: A functional tonB gene is required for both utilization of heme and virulence expression by Haemophilus influenzae type b. Infect Immun 1994, 62(6):2470-2477.

73. Maciver I, Latimer JL, Liem HH, Muller-Eberhard U, Hrkal Z, Hansen EJ: Identification of an outer membrane protein involved in utilization of hemoglobin-haptoglobin complexes by nontypeable Haemophilus influenzae. Infect Immun 1996, 64(9):3703-3712.

74. Morton DJ, Bakaletz LO, Jurcisek JA, VanWagoner TM, Seale TW, Whitby PW, Stull TL: Reduced severity of middle ear infection caused by nontypeable Haemophilus influenzae lacking the hemoglobin/hemoglobinhaptoglobin binding proteins (Hgp) in a chinchilla model of otitis media. Microb Pathog 2004, 36(1):25-33.

75. Morton DJ, Madore LL, Smith A, Vanwagoner TM, Seale TW, Whitby PW, Stull $\mathrm{TL}$ : The heme-binding lipoprotein $(\mathrm{HbpA})$ of Haemophilus influenzae: role in heme utilization. FEMS Microbiol Lett 2005, 253(2):193-199.

76. Morton DJ, Smith A, Ren Z, Madore LL, VanWagoner TM, Seale TW, Whitby PW, Stull TL: Identification of a haem-utilization protein (Hup) in Haemophilus influenzae. Microbiology 2004, 150(Pt 12):3923-3933.

77. Sanders JD, Cope LD, Hansen EJ: Identification of a locus involved in the utilization of iron by Haemophilus influenzae. Infect Immun 1994, 62(10):4515-4525.

78. Hanson MS, Hansen EJ: Molecular cloning, partial purification, and characterization of a haemin-binding lipoprotein from Haemophilus influenzae type b. Mol Microbiol 1991, 5(2):267-278.

79. Vergauwen B, Elegheert J, Dansercoer A, Devreese B, Savvides SN: Glutathione import in Haemophilus influenzae $\mathrm{Rd}$ is primed by the periplasmic heme-binding protein HbpA. Proc Natl Acad Sci U S A 2010, 107(30):13270-13275.

80. Morton DJ, Seale TW, Bakaletz LO, Jurcisek JA, Smith A, VanWagoner TM, Whitby PW, Stull TL: The heme-binding protein $(\mathrm{HbpA})$ of Haemophilus influenzae as a virulence determinant. Int J Med Microbiol 2009, 299(7):479-488.

81. Cain JA, Solis N, Cordwell SJ: Beyond gene expression: The impact of protein post-translational modifications in bacteria. J Proteomics 2014 97:265-286. 